\title{
NOTE ON TRANSLATION AND TRANSLITERATION
}

Writing about people who traveled through the vast multilingual Ottoman Empire and who originated from a wide range of Turkic polities calls attention to both major similarities and differences in how they communicated, wrote, and recorded history. These complexities are embedded in archival sources in Ottoman Turkish and Chaghatay/Turki. A note here is in order to clarify that Chaghatay was a lingua franca of Central Asia (alongside Persian) that was used from the I40os through the I950s and written in Arabo-Persian script. It is distinct from Ottoman and Tatar. In the interest of consistency, I have chosen to transliterate all Central Asian personal names and place names recorded in Ottoman sources according to the modified International Journal of Middle East Studies method. Ottoman Turkish is rendered in modern Turkish with minor exceptions. For transliterating Chaghatay, I use the system for modern Uzbek. In translating passages from Mirim Khan's hajj account, I have stayed true to the original text and have taken only minor liberties with syntax. All manuscript and document translations are my own unless otherwise specified. 


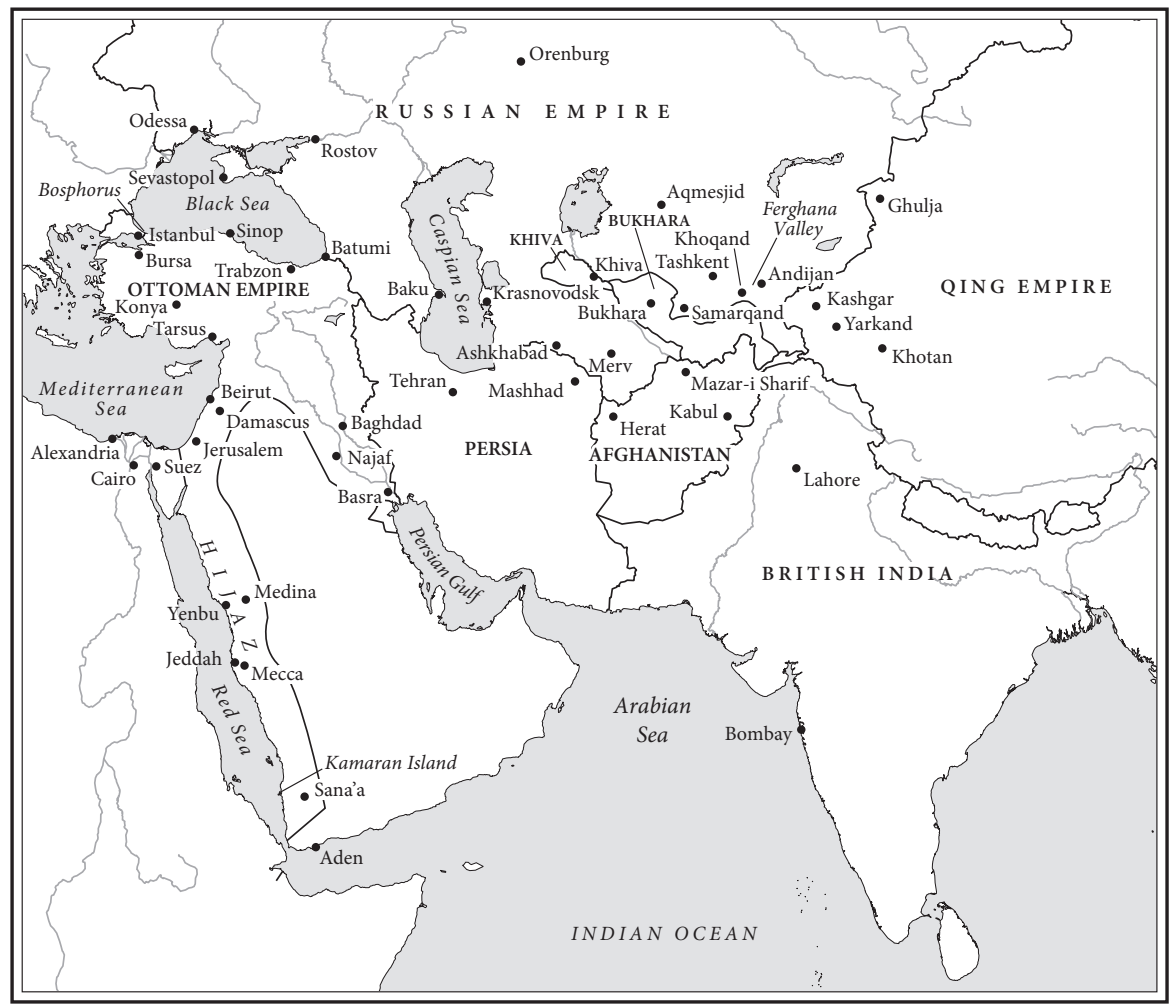

MA P I. Central Asia and the Ottoman Empire in inter-Asian perspective, c. I 900. 
SPIRITUAL SUBJECTS 


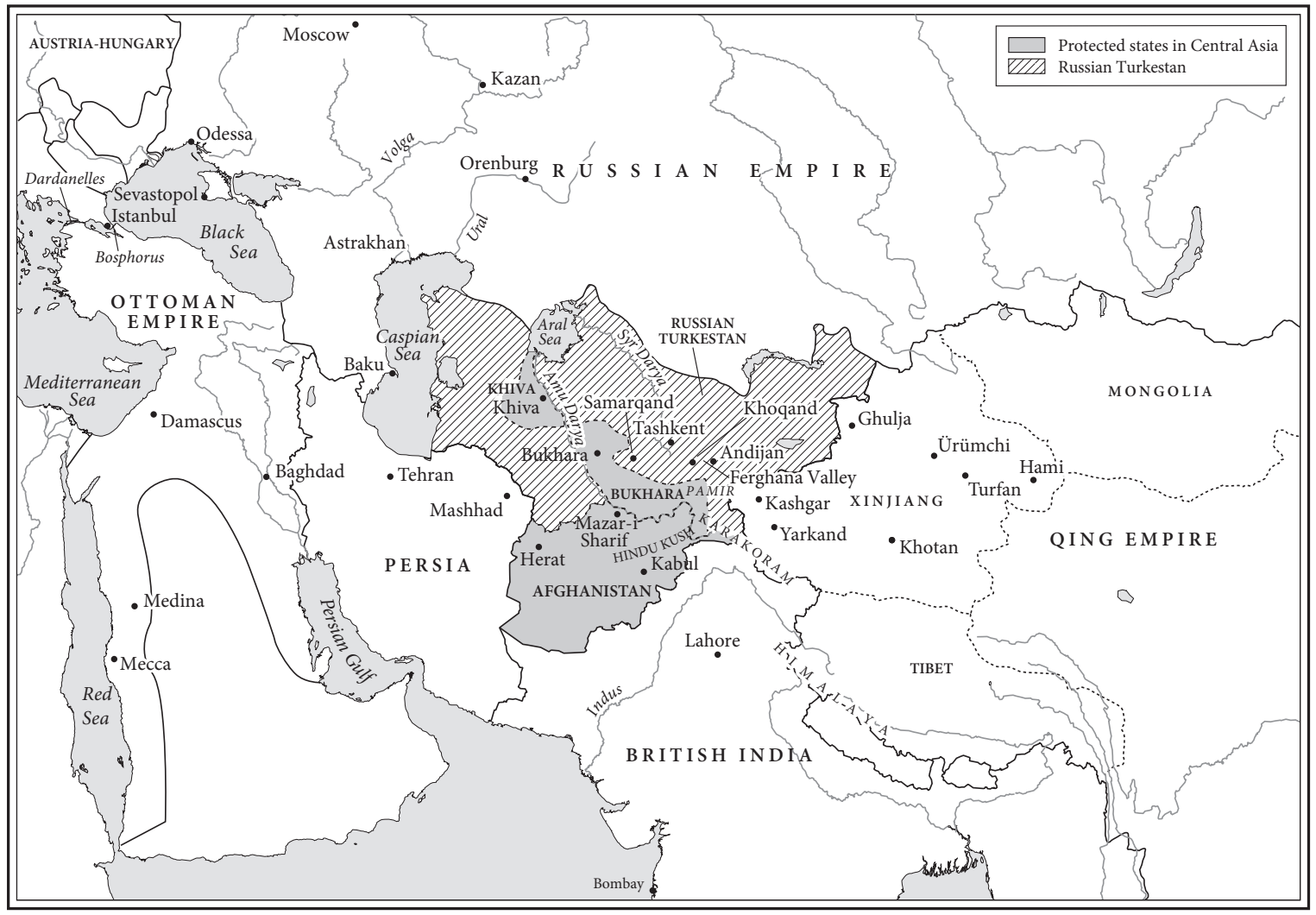

MAP 2. Central Asia political map, early twentieth century. 